\title{
Professional practices, training, and funding mechanisms: A survey of pediatric primary care psychologists
}

\author{
Kathryn W. Hoffses \\ Thomas Jefferson University \\ Andrew R. Riley \\ Oregon Health and Science University \\ Kathryn M. Menousek \\ University of Nebraska Medical Center \\ Kriston B. Schellinger \\ Rady Children's Hospital-San Diego \\ Adlisßnths Grennazipitional works at: https://jdc.jefferson.edu/pedsfp \\ IIniversity of Nebraska Medical Center \\ Part of the Pediatrics Commons, and the Psychiatry and Psychology Commons

\section{Let us know how access to this document benefits you} \\ See next page for additional authors
}

\section{Recommended Citation}

Hoffses, Kathryn W.; Riley, Andrew R.; Menousek, Kathryn M.; Schellinger, Kriston B.; Grennan, Allison 0.; Cammarata, Chrissy; and Steadman, Jason L., "Professional practices, training, and funding mechanisms: A survey of pediatric primary care psychologists" (2017). Department of Pediatrics Faculty Papers. Paper 71.

https://jdc.jefferson.edu/pedsfp/71

This Article is brought to you for free and open access by the Jefferson Digital Commons. The Jefferson Digital Commons is a service of Thomas Jefferson University's Center for Teaching and Learning (CTL). The Commons is a showcase for Jefferson books and journals, peer-reviewed scholarly publications, unique historical collections from the University archives, and teaching tools. The Jefferson Digital Commons allows researchers and interested readers anywhere in the world to learn about and keep up to date with Jefferson scholarship. This article has been accepted for inclusion in Department of Pediatrics Faculty Papers by an authorized administrator of the Jefferson Digital Commons. For more information, please contact: JeffersonDigitalCommons@jefferson.edu. 


\section{Authors}

Kathryn W. Hoffses, Andrew R. Riley, Kathryn M. Menousek, Kriston B. Schellinger, Allison O. Grennan, Chrissy Cammarata, and Jason L. Steadman 
Running head: PROFESSIONAL PRACTICES OF PSYCHOLOGISTS IN PRIMARY CARE

\author{
Professional Practices, Training, and Funding Mechanisms:
}

A Survey of Pediatric Primary Care Psychologists

\begin{abstract}
AUTHORS
Keywords: pediatric primary care, professional practices, integrated service delivery; survey; funding
\end{abstract}

December 7, 2016

Resubmission 


\begin{abstract}
The integration of mental health services in primary care settings has expanded rapidly in recent years with psychologists being at the forefront of efforts to promote healthy behaviors, reduce disease, and care for behavioral, emotional, and developmental needs to promote overall health and well-being for children and families (APA 2014; Stancin \& Perrin, 2014). While there are many psychologists working in pediatric primary care (PPC), little is known about the specific activities that these psychologists engage in, the training they receive, or funding mechanisms that support their work. This study sought to address this gap in the literature through a survey of psychologists working in PPC. An anonymous online survey was disseminated to members of professional organizations and listservs who were identified as having interest in PPC. Sixty-five psychologists currently practicing in PPC completed the survey by reporting on clinical roles and practices, professional training, practice settings, and funding supports in PPC settings. Results indicate that psychologists assume a number of roles in PPC including providing individual and family therapy, conducting screenings for child mental health concerns, and providing consultation to medical colleagues. Many psychologists also provide supervision and offer educational opportunities for those in related fields, such as medicine and social work. Engagement in research activities was identified as a secondary activity. It was reported that a number of clinical activities were not billed for on a regular basis. Additional areas of research will be discussed along with implications for clinical services in PPC.
\end{abstract}




\section{Professional Practices, Training, and Funding Mechanisms: A Survey of Pediatric Primary Care Psychologists}

The integration of mental and physical health services is an essential component in achieving the Triple Aim of healthcare reform: improving patient experience, population health, and cost effectiveness (Berwick, Nolan, \& Whittington, 2008). Many areas of healthcare perform below expectations in the United States, with mental health services being particularly lacking (Schoen, Davis, How, \& Schoenbaum, 2006). In pediatric healthcare, it is estimated that less than half of children in need of mental health treatment receive intervention (Stancin \& Perrin, 2014). Pediatric primary care (PPC) is often the first stop for families with behavioral, emotional, or developmental concerns for their children with 40-70\% percent of people seeking behavioral health services exclusively in primary care (Kessler \& Stafford, 2008). However, pediatric primary care providers (PCPs) face significant barriers to providing behavioral care including insufficient time, inadequate training, and poor reimbursement (Cooper, Valleley, Polaha, Begeny, \& Evans, 2006; Nasir, Watanabe-Galloway, \& DiRenzo-Coffey, 2014; Pidano, Kimmelblatt, \& Neace, 2011). As families often struggle to access mental health services beyond the primary care setting (Schoen, et al., 2006), the integration of physical and mental health services in PPC represents an important effort to address the needs of children and families.

\section{Benefits of Integrated Care}

Research on integrated primary care (IPC) has identified benefits in each domain of the Triple Aim. With regards to patient experience, the IPC model improves accessibility of mental health services in a non-stigmatizing environment (Barber, Frantsve, Capelli, \& Sanders, 2011; Burt, Garbacz, Kupzyk, Frerichs, \& Gathje, 2014; Chomeinne et al., 2010). In pediatric and mixed-age populations, patients and PCPs report increased satisfaction when psychologists are available onsite to address mental health concerns (Chomienne, et al., 2010; Cooper, et al., 2006; Cummings, et al., 2009). The presence of 
behavioral health providers also allows for families to discuss a greater number of topics during healthcare visits (Burt et al., 2014).

Research evidence for the efficacy of IPC on pediatric health outcomes is growing. In a recent meta-analysis, Asarnow, Rozenman, Wiblin, and Zeltzer (2015) reported a small, statistically significant advantage of IPC models compared to traditional outpatient mental health services. Studies have demonstrated improved outcomes for depression, anxiety, chronic pain, and disruptive behavior problems when treated in IPC settings (Bower, 2006; Perrin, Sheldrick, McMenamy, 2014).

Across the age span, IPC enhances PCP efficiency, generates revenue, and reduces medical costs (Monson, Sheldon, Ivey, Kinman, \& Beacham, 2012). Cost savings range from $\$ 1700-\$ 2900$ per person when mental and physical health needs are addressed together (Chiles, Lambert, \& Hatch, 1999). Integration also reduces the time PCPs spend addressing mental health concerns, thereby increasing physician efficiency (Burt, et al., 2014; Cooper, 2006; Cummings, Odonahue, and Cummings 2009).

\section{Models of Integration in Primary Care}

While evidence for the benefits of IPC in pediatric settings has increased, questions remain regarding how IPC is best achieved in practice. One framework for characterizing IPC describes three different levels of integration: Coordinated, Co-located, and Integrated (Blount, 2003; Vogel, Malcore, Illes, \& Kirkpatrick, 2014). In Coordinated models, psychologists and physicians work in separate settings and engage in separate work activities, but communicate about shared patients. Co-located models feature psychologists and physicians working in the same setting, but not necessarily the same office. They primarily engage in separate activities, but may interact through consultation about shared or complex patients or through warm handoffs. Finally, in Integrated models, psychologists and physicians are located in the same office, frequently engage in in-person communication, and work as team to address the needs of shared patients. In essence, psychology is viewed as part of general 
pediatrics care rather than a separate service. It is important to note that these categories of integration are not mutually exclusive, and are often viewed as a continuum across activities (Stancin, 2005).

\section{Rationale for the Current Study and Study Aims}

While healthcare reform has led to significant growth of IPC and several models of IPC practice have been described in the literature, little is known regarding how pediatric psychologists are operating in every day practice. Given the relative novelty of IPC, understanding the daily activities of psychologists working in PPC settings, as well as their training backgrounds, skills, and funding mechanisms is important to informing future efforts in research, education, practice, and policy. The purpose of this study was to survey psychologists in PPC in order to better understand their training backgrounds, practice patterns, other professional roles, and funding mechanisms.

\section{Method}

\section{Survey Development}

The survey was designed to assess professional practices of psychologists working in PPC. Survey domains were identified through a literature review focused on current trends in PPC professional training, service delivery, and funding mechanisms. Literature from relevant pediatric psychology settings (e.g., inpatient consultation/liaison) was also considered given overlap in practices (e.g., brief screenings, frequent consultation with medical providers). Survey items were developed, pooled together, piloted amongst study authors, and revised. Psychologist colleagues with various levels of experience in PPC who were not associated with the study completed the initial version of the survey and provided feedback, which was incorporated into the final version. Branching logic was used so that participants only completed portions of the survey that were applicable to their current position (e.g., participants only completed items about teaching if they indicated that teaching was one of their professional roles). Survey items are available as an online supplement. 


\section{Procedures}

This study was approved by the Institutional Review Board (IRB) of Oregon Health \& Science University and determined to be exempt from further oversight by the University of Nebraska Medical Center and Nemours/A.I. duPont Hospital for Children. IRB approval was only obtained from these institutions as only authors who were affiliated with these institutions were involved in data collection, analysis, and storage. Study data were collected and managed using REDCap electronic data capture tools hosted at Oregon Health \& Science University. REDCap (Research Electronic Data Capture) is a secure, web-based application designed to support data capture for research studies, providing 1) an intuitive interface for validated data entry; 2) audit trails for tracking data manipulation and export procedures; 3) automated export procedures for seamless data downloads to common statistical packages; and 4) procedures for importing data from external sources (Harris et al., 2009). Participants were eligible to complete the survey if they were licensed psychologists who spent at least $10 \%$ of their professional time (i.e., at least four hours in a given week) in primary care with at least $25 \%$ of their time devoted to pediatric patients, or provided supervision to trainees in PPC that met this criterion. Unlicensed trainees and non-psychology providers were not eligible to participate. All responses were anonymous and participants were allowed to skip items if they wished. To maintain anonymity, no email addresses or other identifying information were recorded with survey results. To identify potential duplicates, demographic item responses were screened for identical entries. No duplicates were identified.

Recruitment. An effort was made to distribute the survey as widely as possible to ensure adequate representation of PPC psychologists across the country. The authors contacted administrators from a number of relevant national professional societies and state psychological associations for permission to recruit within their membership. Ultimately, permission to recruit was obtained from the 
Collaborative Family Healthcare Association, the IPC Special Interest Group (SIG) of Division 38 (Health Psychology) of the American Psychological Association (APA), and several SIG leaders through APA Division 54 (Pediatric Psychology). The Division 54 SIGs that authors sought permission from were Adherence, Adolescent and Young Adult, Consultation/Liaison, Diversity, and Obesity. These SIGs were contacted due to their membership size and overlap with IPC services. IPC SIG members were also surveyed. Potential participants were recruited via listserv postings containing an invitation to participate and electronic link to the survey. The recruitment email was posted on each listserv three times over the course of one month. The survey closed four weeks after the initial recruitment email was sent.

In addition to those memberships, potential participants were recruited via internship and postdoctoral training programs that offer IPC experiences from a list maintained by the past co-chairs of the IPC SIG. The list was most recently updated in May 2016 in advance of this survey being distributed in June 2016. Three email invitations were sent to the primary contact identified by the training programs over the course of one month. In total, 76 training program representatives were contacted. Nine email addresses were undeliverable. Eight of the remaining 68 programs (13\%) completed some portion of the survey. As the REDCap system does not identify participants beyond those to whom the invitation was originally sent, it is unclear what proportion of participants were recruited from this pool, nor is it clear what proportion of recipients were eligible to participate. Overall, it is estimated that more than 2,000 individuals across the country received this survey invitation; however, what proportion of these individuals viewed the invitation or were eligible to participate is unknown. It is in fact unclear how many psychologists in the United States are currently working in PPC, and as such it is difficult to estimate population parameters.

\section{Participants}


A total of 81 survey entries were created, meaning a potential participant opened a link to complete the survey. Of those, 67 entries were eligible based on responses to inclusion criteria items. Two entries contained no responses beyond those for eligibility screening. Thus, the overall sample consisted of 65 original respondents. Table 1 summarizes demographic and professional characteristics of the sample.

\section{Data Analysis}

Descriptive statistics were calculated with SPSS v.22 software package to characterize the information gathered.

\section{Results}

Participants represented practicing psychologists in 25 states with all regions of the country represented. The sample ranged from less than one year to 37 years post-licensure, but early-career psychologists were most common $(M d n=4, \mathrm{IQR}=2,8)$. Participants reported a mean $63 \%$ FTE $(S D$ $=29.3 \%$; range: $10 \%-100 \%$ ) providing services in primary care. Provision of direct clinical services was reported as the most common role (81\%), followed by clinical supervision (11\%), grant work (5\%), teaching (2\%), and administrative work (2\%). At least one secondary role was reported by $99 \%$ of the sample, consisting of clinical supervision (55\%), teaching (55\%), administrative work (45\%), research (39\%), direct clinical work (11\%) and grant work (8\%). Five participants wrote in "consulting" when asked to provide a description after they indicated "other."

\section{Primary Care Training and Experience}

Including training prior to licensure, participants reported working in primary care for a mean of 6.9 years $(S D=7.0$; range $0-41)$. Specialized training in PPC prior to licensure was reported by $63 \%$ of the sample and most commonly occurred during internship $(n=29)$ or postdoctoral fellowship $(n=28)$. 
Specialized training in PPC post-licensure was reported by $75 \%$ of the sample and most commonly took place through continuing education credits $(n=39)$ or webinars $(n=24)$.

\section{Clinical Supervision}

Participants reported providing clinical supervision as a primary or secondary role in 43 cases (66\%). Pre-doctoral intern was the most common type of supervisee $(65 \%)$, followed by post-doctoral fellow (54\%), and extern/graduate student (42\%). Participants reported a range of 1-7 psychology trainees, with 1 or 2 being most common ( $86 \%$ of cases). Supervisees from disciplines other than psychology were reported by 15 participants, including medicine (80\%), social work (40\%), and allied health professionals (20\%). Psychologists endorsed providing supervision in individual (54\%), group (40\%), direct observation (40\%), co-therapy/consultation (33\%), and telehealth (9\%) formats.

\section{Clinical Setting Characteristics}

Table 2 shows the clinical settings endorsed by participants for both their own direct IPC practice and that of their clinical supervisees. For psychologists, academic medical centers (38\%) and private outpatient medical practices $(27 \%)$ were most frequently identified by participants as their primary clinical settings. A strong majority $(82 \%)$ reported practicing in a single primary care setting, $15 \%$ reported practicing in two settings, and $4 \%$ reported three or more settings. Clinical supervisees were also most likely to operate in academic medical centers (45\%), followed by hospital affiliated community clinics $(21 \%)$. Clinic settings were most often located in urban communities (47\%).

Models of integration. Participants were asked to categorically identify their IPC model of practice as Coordinated, Co-Located, or Integrated as defined by Blount (2003). A majority of respondents endorsed Integrated (63\%), followed by Co-located (31\%), and Coordinated (6\%). Participants also rated their practice on the dimensions of coordination, co-location, and integration on a 4-point Likert scale ranging from "not at all" to "fully." With regards to coordination (i.e., the degree of 
information exchanged between medical and psychological providers for purposes of patient care), participants rated their practice a mean 3.27/4 ( $S D=.68)$. On the dimension of co-location (i.e., the physical proximity for medical and psychological services), participants provided a mean rating of 3.67/4 (SD=.64). Ratings of integration (i.e., the extent that psychological services are delivered as a part of general pediatric care) averaged 2.95/4 ( $S D=.87)$.

Services provided. Table 3 summarizes participant ratings of the types of presenting concerns addressed in PPC and services provided by psychologists and psychologists' supervisees. Frequency ratings were provided on a 4-point Likert scale ranging from "never" to "always." Behavioral and mental health concerns were the most frequently represented, followed by parent/family concerns, developmental concerns, chronic medical conditions, and acute medical conditions.

Screening. Most participants reported at least "sometimes" being involved in screening in primary care. Amongst those involved directly in screening, child mental health screeners (e.g., PHQ-9) were most commonly endorsed (74\%), in addition to autism screening (e.g., M-CHAT; 32\%), parent mental health screeners (25\%), and developmental screeners (22\%). With regards to screeners used in the IPC setting by medical professionals other than psychologists, child mental health screeners were most commonly endorsed (71\%), followed by child development (60\%), autism (59\%), and parent mental health screeners (40\%).

Assessment. Most IPC psychologists reported at least sometimes providing diagnostic evaluations. Amongst those who reported providing diagnostic evaluations ( $\mathrm{n}=40)$, testing for ADHD was most commonly endorsed (95\%), followed by testing for developmental disabilities (30\%), and psychoeducational testing (28\%). 
Therapy. A strong majority of psychologists in IPC reported providing therapeutic services “often" or "sometimes." A limit on sessions was reported by $32 \%$ of the sample, with a range of a 3-10 session limit $(M=5.59 ; S D=2.12)$.

Consultation. Consultation was defined for this survey as "contribution to patient care without entering into a formal therapeutic relationship" (e.g., advising the treating physician, brief assessment and recommendations made during medical care, anticipatory guidance in well-child care). Nearly all psychologists (92\%) reported "sometimes" or "often" engaging in consultation, with clinical supervisees engaging in consultation activities slightly less frequently (79\%).

\section{Compensation and Productivity}

A majority of participants reported their work in IPC is funded through clinical billing (57\%). Departmental funds (39\%), grants (31\%), training awards (9\%), state funding (9\%), and private practice budgets $(3 \%)$ were also endorsed. Donations/endowments were specified as other sources of funding $(n=2)$. A small portion $(5 \%)$ of the sample reported the majority of their work was unfunded.

Compensation. Specific clinical productivity requirements were reported by $64 \%$ of the sample. Salary dependent on performance outcomes were indicated by $19 \%$ of participants and $23 \%$ reported having some financial incentive to meet productivity requirements. Relative Value Units (RVUs; 82\%), Press Ganey metrics (46\%), and other methods (9\%) were endorsed as measures of performance outcomes. Scholarly productivity (62\%) in addition to RVUs (85\%), Press Ganey (39\%), and other metrics $(23 \%)$ were endorsed as measures of productivity.

Billing. Generating funding through clinical billing was endorsed by $61 \%$ of the sample. A majority of participants reported billing for diagnostic evaluations (74\%), individual therapy (72\%), and family therapy (65\%); followed by emotional/behavioral screening (32\%), initial consultations/warm handoffs (32\%), developmental screenings (28\%), and group therapy (23\%). 
Current Procedural Terminology (CPT) psychotherapy codes were used most frequently (80\%, “often”), followed by Health and Behavior (HB) codes (19\%, “often”). Use of consultation codes (2\%) and "other" codes (e.g., testing codes, evaluation, and management codes; 10\%) was less common. Participants reported collecting payment from Medicaid (76\%), Tricare (53\%; 20\% unsure), private insurances $(79 \% ; 2 \%$ unsure), self-pay (67\%; 3\% unsure), and other insurances (16\%). Preauthorization from insurances as a requirement to see patients in PPC was reported by $10 \%$ of the sample, with $15 \%$ unsure, and 35\% endorsing preauthorization dependent on insurance coverage.

Not billing for any clinical services was endorsed by $12 \%$ of the sample and $48 \%$ indicated that at least some clinical services are provided free of charge. With regards to consultation in particular, free-of-charge services were reported by $32 \%$ of participants for consultations with families that were less than 15 minutes, $74 \%$ of consultations with families lasting more than 15 minutes, $72 \%$ of consultations with a medical colleague, and $65 \%$ of consultations with outside agencies.

With regards to whether clinical services provided by trainees are billed for, $23 \%$ of supervisors indicated services are unbilled, 19\% endorsed "sometimes" dependent on the level of trainee (e.g., resident versus fellow), 53\% indicated services are billed under the supervisor's license, and 7\% reported services are billed under the trainee's license.

\section{Teaching}

Thirty-six participants completed the section on teaching. As noted in Table 4, a mean of 4.0 hours $(S D=4.88)$ per week were devoted to psychology-specific training, with group supervision $(56 \%)$, informal lectures (56\%), formal lectures (50\%), workshops (33\%), and grand rounds (25\%) being endorsed as didactics given in the past year. Participants reported providing teaching to other disciplines a mean of 3.1 hours $(S D=5.7)$ per week, and endorsed providing didactics in the past year in the form of informal lectures (67\%), formal lectures (58\%), grand rounds (30\%), workshops (36\%), and group 
supervision (19\%). Other disciplines in attendance for those didactics were reported as medicine $(83 \%)$, nursing and medical assistance (36\%), social work (33\%), clinical support staff (22\%), counselors (17\%), behavioral analysts $(6 \%)$, and “other" $(14 \%)$. Respondents identified the following sources of support for teaching: support from non-psychology departments (39\%), grant funding (36\%), psychology department funding (31\%), clinical billing revenues (25\%), and “other" (3\%). Teaching being unfunded was reported by $28 \%$ of the participants.

\section{Research}

Twenty-five participants (38\%) identified research in primary care as a primary or secondary role. Of those, $88 \%$ reported conducting research in primary care "sometimes" or "often." Respondents endorsed institutionally protected FTE (36\%), external grant funding (24\%), internal grant funding (20\%), provision of research assistants (12\%), and working at a dedicated research institute (8\%) as sources of research support. Most participants indicated their IPC research was not funded (40\%).

\section{Discussion}

This study is the first to examine professional practices of psychologists working in PPC. Survey results suggest that PPC psychologists generally represent a younger workforce, with early career psychologists being the most common among those practicing in primary care. Given the growth of health care initiatives focused on increasing the number of psychologists providing mental health services in primary care, it is not surprising that newer professionals are pursuing employment in this area. To support this growing contingent of psychologists, advancements in training, translational science, and professional advocacy are needed.

Training in PPC prior to licensure, usually through internship or postdoctoral training, was reported by more than half of survey participants. This may reflect recognition of the growing need for specialty IPC training opportunities, or indicate that survey participants represent the current "gold 
standard" of training (i.e., specialized residency or fellowship training in PPC). Regardless, robust training experiences will continue to be essential. Guidelines describing specific competencies for psychologists in PPC are emerging (Hoffses et al., 2016) and may serve as a blueprint for training psychologists to function in PPC settings. There is strong potential for graduate programs to expose psychology students to the emerging field of PPC psychology, and increased funding through Health Resources and Services Administration (HRSA) training grants also presents an opportunity for developing new curricula across levels of training.

Psychologists also play a prominent role in training students and professionals in other disciplines. Results of this survey indicate that clincal supervision and teaching was primarily conducted with students in the field of psychology, but also occurred with individuals from other disciplines (e.g., medical students, social workers), suggesting that psychologists in PPC often engage in interprofessional collaboration which goes beyond consultation as part of their clinical practice. As the healthcare environment continues to emphasize a team-based approach, psychologists offer a valuable contribution to establishing and executing collaborative training environments (Polaha, Schetzina, \& Baker, 2016).

With regards to clinical practice, the most commonly reported presenting concerns were similar to those seen in traditional outpatient settings (e.g., mental health concerns, family difficulties), but PPC psychologists also reported providing services surrounding developmental concerns. These findings suggest that psychologists working in PPC must possess a broad knowledge base for developmental, physical, behavior, and emotional concerns. Psychologists in PPC have the unique opportunity to assist in establishing systems of care, including identifying and implementing screening procedures, interpreting data, and facilitating referrals to specialists outside a patient's medical home.

Nearly all participants endorsed engaging in consultation services and screening efforts; both activities suggestive of a high level of integration and clearly distinct from the traditional practice of 
specialty mental health. This finding is interesting in contrast to the recent meta-analytic findings by Asarnow et al. (2015). Just 5 of 31 studies included in that meta-analysis were categorized as collaborative care, defined by Asarnow et al. as a "team of behavioral health care professionals and PCPs work[ing] collaboratively in fully or partly integrated system" (Asarnow et al. pp. 931). All five of those studies (Asarnow et al., 2005; Clarke et al., 2005; Kolko et al., 2014; Kolko, Campo, Kilbourne, \& Kelleher, 2012; Richardson et al., 2014) involved the provision of psychological services to defined clinical groups (e.g., depressed adolescents) delivered separate from usual medical care (e.g., group therapy in the clinic waiting room after usual hours), and can generally be considered high on dimensions of collaboration and co-location, but lower with regards to integration as defined by Blount (2003). In fact, though Asarnow et al. used different terminology than Blount, none of the 31 randomized clinical trials (RCTs) included in that meta-analysis can be characterized as highly integrated as defined herein. By contrast, the results of this study suggest that psychologists are often engaging in highly integrated practices for which there is little empirical guidance. For instance, psychologists in highly integrated models may conduct screenings and provide brief support or anticipatory guidance during consultations with families for a particular concern as part of well-child care (Talmi \& Fazio, 2012). Currently, there is little empirical evidence to inform how such care is best delivered or whether such consultations produce positive outcomes.

The apparent discrepancy between clinical practice and empirical literature is likely partially due to a rapidly changing healthcare landscape that has only recently emphasized the integration of medical and behavioral care (Rozensky \& Janicke, 2012). In fee-for-service settings, reliance on psychotherapy or testing CPT codes (which generally require a mental health diagnosis for reimbursement) has likely limited the degree to which psychologists permeated general pediatrics populations. The advent of HB codes and other alternative forms of payment provides an opportunity for psychologist to not only 
address psychopathology, but promote behavioral and physical health in the general population (Talmi \& Fazio, 2012). As practice parameters change, researchers will be challenged to identify behavioral practices that are not only efficacious, but pragmatic and externally valid. More than one third of participants reported engaging in research, and practice-based research methodologies that engage clinicians to balance internal and external validity may provide one avenue forward (Westfall, Mold, \& Fagnan, 2007). Funding and revenue sources also represent an area of continued emphasis, as much work in PPC was not billed or reimbursed. Although over half of psychologists reported that they generated funding through clinical services, only three-fourths regularly billed for diagnostic evaluations, individual, and family therapy. Additionally, a majority of participants engaged in consultation and screening on a daily basis, but these services often were not reimbursed or were provided for free. Services provided by trainees were often unbilled. Interestingly, over half of participants noted that their salary was contingent on clinical productivity, but also reported inability to bill for the full range of services provided. To maintain viability in PPC, it is crucial that psychologists be able to appropriately bill for services and generate revenue comparable to medical colleagues (Tynan, 2016). Advocacy for the benefits of psychologists in PPC and empirical demonstration of Triple Aim outcomes are essential to this effort.

\section{Limitations}

Several study limitations should be considered in the interpretation of these findings. The small sample size limits generalizability of results, and given recruitment through specialty professional organizations and that $55 \%$ of the sample reported an academic rank, it may be that the sample captured is more representative of individuals on the forefront of IPC efforts than the typical practitioner. An additional weakness is the use of a survey instrument created for the purposes of this study that relied heavily on estimates from psychologists rather than objective data. Future efforts would be aided by the 
development and utilization of psychometrically sound measures of domains such as level of integration or billing practices. Finally, the data obtained left many questions unanswered. For example, while it was learned that consultation is highly common, the nature of that consultation (i.e., families, physicians) or relative time spent in those activities cannot be derived from the information gathered. Future investigations could focus on more nuanced aspects of PPC integration.

\section{Conclusions}

Despite limitations, this study represents an important first step in understanding the current work force and practice trends in PPC environments. Just as participants reported a variety of professional roles, psychologists in PPC must reach across traditional silos to move the field forward. Practitioners' perspectives are critical to informing a pragmatic science of IPC. That science will be imperative in advocating for financial models that secure the place of psychologists in PPC along with ensuring that effective training models are developed to guide future practice.

Due to the changing landscape of healthcare, PPC psychology is likely to grow exponentially in future years. There is great enthusiasm for work in PPC as evidenced by large numbers of early career professionals entering this arena, increased funding opportunities, training programs, internships, and postdoctoral fellowships that aim to prepare a workforce to function in primary care. Better understanding for how to provide services to meet the needs of children and adolescents in primary care is necessary to ensure the sustainability of this work, and to reach millions of children and families who may otherwise not have access to these valuable services. 
Table 1

Sample Characteristics $(N=65)$

\begin{tabular}{lll}
\hline Characteristic & $n(\%)$ & $M \pm S D$ \\
\hline Age, years & & $38.2 \pm 9.3$ \\
Gender & & \\
Male & $14(22 \%)$ & \\
Female & $51(79 \%)$ & \\
Race & & \\
African American & $3(5 \%)$ & \\
Asian/Pacific Islander & $2(3 \%)$ & \\
Caucasian/White & $58(89 \%)$ & \\
Bi-racial & $1(2 \%)$ & \\
Other & $2(3 \%)$ & \\
Ethnicity & & \\
Hispanic/Latino & $4(6 \%)$ & \\
Non-Hispanic/Latino & $54(83 \%)$ & \\
Other & $4(6 \%)$ & \\
Prefer not to answer & $2(3 \%)$ & \\
Highest degree obtained & & \\
PhD & $50(77 \%)$ & \\
PsyD & $14(22 \%)$ & \\
Other & $1(2 \%)$ & \\
Theoretical Orientation & $18(28 \%)$ & \\
Behavioral & $0(0 \%)$ & \\
Biological & $28(43 \%)$ & \\
Cognitive-behavioral & $7(11 \%)$ & \\
Eclectic & $1(2 \%)$ & \\
Humanistic/Existential & $6(9 \%)$ & \\
Integrative & $1(2 \%)$ & \\
Interpersonal & & \\
Psychodynamic/Psychoanalytic & & \\
Systems & & \\
Years since licensure & & \\
Academic Rank & & \\
Assistant Professor & & \\
Associate Professor & & \\
Full Professor & & \\
None & & \\
\hline
\end{tabular}


Table 2

Characteristics of Psychologists' and Supervisees' Primary Care Practice Settings

Characteristic $\quad$ Psychologists Supervisees

Number of primary care settings

One

$82 \% \quad$ N/A

Two

$15 \%$

N/A

Setting characteristics

Academic medical center

$38 \% \quad 45 \%$

Private outpatient medical practices

$27 \% \quad 18 \%$

Hospital-affiliated community clinics

$16 \% \quad 21 \%$

Other community clinics not affiliated with hospitals

$9 \% \quad 8 \%$

Private hospitals

$3 \% \quad 0 \%$

Military Primary Care

$4 \%$

$0 \%$

Federally Qualified Health Center

$28 \%$

$18 \%$

Surrounding community

Urban

$38 \%$

$47 \%$

Suburban

$35 \%$

$32 \%$

Rural

$27 \%$

$21 \%$ 
Table 3

Psychologists' Frequency Ratings of Presenting Concerns and Clinical Services Delivered by Themselves and Supervisees

\begin{tabular}{|c|c|c|c|c|c|c|c|c|}
\hline \multirow[b]{2}{*}{ Variable } & \multicolumn{4}{|c|}{ Psychologists $(n=53)$} & \multicolumn{4}{|c|}{ Supervisees $(n=38)$} \\
\hline & Never & Rarely & Sometimes & Often & Never & Rarely & Sometimes & Often \\
\hline Presenting concerns & & & & & & & & \\
\hline Child behavioral/mental health & $0 \%$ & $0 \%$ & $2 \%$ & $98 \%$ & $3 \%$ & $0 \%$ & $3 \%$ & $95 \%$ \\
\hline Child developmental & $0 \%$ & $13 \%$ & $45 \%$ & $42 \%$ & $3 \%$ & $16 \%$ & $42 \%$ & $40 \%$ \\
\hline Chronic medical & $2 \%$ & $36 \%$ & $45 \%$ & $17 \%$ & $3 \%$ & $38 \%$ & $49 \%$ & $11 \%$ \\
\hline Acute medical & $11 \%$ & $57 \%$ & $21 \%$ & $11 \%$ & $13 \%$ & $61 \%$ & $8 \%$ & $18 \%$ \\
\hline Parent or family concerns & $0 \%$ & $2 \%$ & $15 \%$ & $83 \%$ & $3 \%$ & $3 \%$ & $16 \%$ & $79 \%$ \\
\hline Diagnostic evaluations & $25 \%$ & $6 \%$ & $23 \%$ & $47 \%$ & $29 \%$ & $0 \%$ & $26 \%$ & $45 \%$ \\
\hline Screening & $2 \%$ & $8 \%$ & $33 \%$ & $58 \%$ & $3 \%$ & $14 \%$ & $24 \%$ & $60 \%$ \\
\hline Therapy & $2 \%$ & $17 \%$ & $9 \%$ & $72 \%$ & $8 \%$ & $8 \%$ & $21 \%$ & $63 \%$ \\
\hline Consultation & $0 \%$ & $8 \%$ & $45 \%$ & $47 \%$ & $5 \%$ & $16 \%$ & $32 \%$ & $47 \%$ \\
\hline
\end{tabular}


Table 4

Psychologists' Reported Teaching Practices

\begin{tabular}{lc}
\hline Teaching activity & Percent endorsed \\
\hline Psychology-specific training & $56 \%$ \\
Group supervision & $56 \%$ \\
Informal lectures & $33 \%$ \\
Forkshops & $50 \%$ \\
Grand rounds & $25 \%$ \\
Other disciplines & \\
Informal lectures & $67 \%$ \\
Formal lectures & $58 \%$ \\
Grand rounds & $30 \%$ \\
Workshops & $36 \%$ \\
Group supervision & $19 \%$ \\
Disciplines in attendance & \\
Medicine & \\
Nursing and medical assistance & $36 \%$ \\
Social work & $33 \%$ \\
Clinical support staff & \\
Counselors & \\
Behavior analysts & \\
Other & \\
\hline
\end{tabular}




\section{References}

Asarnow, J. R., Jaycox, L. H., Duan, N., LaBorde, A. P., Rea, M. M., Murray, P., ... Wells, K. B. (2005). Effectiveness of a quality improvement intervention for adolescent depression in primary care clinics: a randomized controlled trial. JAMA, 293(3), 311-319. doi:10.1001/jama.293.3.311

Asarnow, J. R., Rozenman, M., Wiblin, J., \& Zeltzer, L. (2015). Integrated medical-behavioral care compared with usual primary care for child and adolescent behavioral health. JAMA Pediatrics, 169(10), 929-937. doi:10.1001/jamapediatrics.2015.1141

Barber, J. A., Frantsve, L. M., Capelli, S., \& Sanders, K. A. (2011). Implementation and evaluation of an integrated care program in a VA medical center. Psychological Services, 8(4), 282-293. doi:10.1037/a0026158

Berwick, D. M., Nolan, T. W., \& Whittington, J. (2008). The Triple Aim: Care, health, and cost. Health Affairs, 27(3), 759-769. doi:10.1377/hlthaff.27.3.759

Blount, A. (2003). Integrated Primary Care: Organizing the Evidence. Families, Systems, \& Health, 21(2), 121-133. doi:10.1037/1091-7527.21.2.121

Bower, P., Gilbody, S., Richards, D., Fletcher, J., \& Sutton, A. (2006). Collaborative care for depression in primary care: Making sense of a complex intervention: Systematic review and metaregression. The British Journal of Psychiatry, 189(6), 484-493. doi:10.1192/bjp.bp.106.023655

Burt, J. D., Garbacz, S. A., Kupzyk, K. A., Frerichs, L., \& Gathje, R. (2014). Examining the utility of behavioral health integration in well-child visits: Implications for rural settings. Families, Systems, \& Health, 32(1), 20-30. doi:10.1037/a0035121

Chiles, J. A., Lambert, M. J., \& Hatch, A. L. (1999). The impact of psychological interventions on medical cost offset: A meta-analytic review. Clinical Psychology: Science and Practice, 6(2), 204-220. 
Chomienne, M., Grenier, J., Gaboury, I., Hogg, W., Ritchie, P., \& Farmanova-Haynes, E. (2010). Family doctors and psychologists working together: Doctors' and patients' perspectives. Journal of Evaluation in Clinical Practice, 17(2), 282-287. doi:10.1111/j.1365-2753.2010.01437.x

Clarke, G., Debar, L., Lynch, F., Powell, J., Gale, J., O'Connor, E., . . Von Korff, M. (2005). A randomized effectiveness trial of brief cognitive-behavioral therapy for depressed adolescents receiving antidepressant medication. Journal of the American Academy of Child \& Adolescent Psychiatry, 44(9), 888-898.

Cooper, S., Valleley, R. J., Polaha, J., Begeny, J., \& Evans, J. H. (2006). Running out of time: physician management of behavioral health concerns in rural pediatric primary care. Pediatrics, 118(1), 132138. doi:10.1542/peds.2005-2612

Cummings, N. A., O’Donohue, W. T., \& Cummings, J. L. (2009). The financial dimension of integrated behavioral/primary care. Journal of Clinical Psychology in Medical Settings, 16(1), 31-39. doi:10.1007/s10880-008-9139-2

Harris, P.A., Taylor, R., Thielke, R., Payne, J., Gonzalez, N., \& Conde, J.G. (2009). Research electronic data capture (REDCap); A metadata-driven methodology and workflow process for providing translational research informatics support. Journal of Biomedical Information, 42 (2), 377-381.

Hoffses, K. W., Ramirez, L. Y., Berdan, L., Tunick, R., Honaker, S. M., Meadows, T. J., ... \& Stancin, T. (2016). Topical Review: Building Competency: Professional Skills for Pediatric Psychologists in Integrated Primary Care Settings. Journal of Pediatric Psychology, 41(10), 1144-1160.

Kessler, R., \& Stafford, D. (2008). Primary care is the de facto mental health system. In Collaborative medicine case studies (pp. 9-21). Springer New York.

Kolko, D. J., Campo, J., Kilbourne, A. M., Hart, J., Sakolsky, D., \& Wisniewski, S. (2014). Collaborative care outcomes for pediatric behavioral health problems: a cluster randomized trial. Pediatrics, 133(4), e981-992. doi:10.1542/peds.2013-2516 
Kolko, D. J., Campo, J. V., Kilbourne, A. M., \& Kelleher, K. (2012). Doctor-office collaborative care for pediatric behavioral problems: a preliminary clinical trial. Arch Pediatr Adolesc Med, 166(3), 224-231. doi:10.1001/archpediatrics.2011.201

Monson, S. P., Sheldon, J. C., Ivey, L. C., Kinman, C. R., \& Beacham, A. O. (2012). Working toward financial sustainability of integrated behavioral health services in a public health care system. Families, Systems, \& Health, 30(2), 181-186. doi:10.1037/a0028177

Nasir, A., Watanabe-Galloway, S., \& DiRenzo-Coffey, G. (2014). Health services for behavioral problems in pediatric primary care. J Behav Health Serv Res. doi:10.1007/s11414-014-9450-7

Perrin, E. C., Sheldrick, R. C., McMenamy, J. M., Henson, B. S., \& Carter, A. S. (2014). Improving parenting skills for families of young children in pediatric settings. JAMA Pediatrics, 168(1), 16-24. doi:10.1001/jamapediatrics.2013.2919

Pidano, A. E., Kimmelblatt, C. A., \& Neace, W. P. (2011). Behavioral health in the pediatric primary care setting: Needs, barriers, and implications for psychologists. Psychological Services, 8(3), 151.

Polaha, J., Schetzina, K., \& Baker, K. (2016). A Collaborative Practice Training Model for Pediatric Primary Care. International Journal of Health Sciences Education, 3(2), 6.

Richardson, L. P., Ludman, E., McCauley, E., Lindenbaum, J., Larison, C., Zhou, C., .. . Katon, W. (2014). Collaborative care for adolescents with depression in primary care: a randomized clinical trial. JAMA, 312(8), 809-816. doi:10.1001/jama.2014.9259

Rozensky, R. H., \& Janicke, D. M. (2012). Commentary: Healthcare reform and psychology's workforce: preparing for the future of pediatric psychology. Journal of Pediatric Psychology, 37(4), 359-368. doi:10.1093/jpepsy/jsr111 [doi]

Schoen, C., Davis, K., How, S. K., \& Schoenbaum, S. (2006). U.S. health system performance: A national scorecard. Health Affairs, 25(6), w457-w475. doi:10.1377//hlthaff.25.w457 
Stancin, T. (2005). Mental health services for children in pediatric primary care settings. In R. G. Steele \& M. C. Roberts (Eds.), Handbook of mental health services for children, adolescents, and families (pp. 85-101). Cleveland, Ohio: Kluwer Academic/Plenum Publishers.

Stancin, T., \& Perrin, E. C. (2014). Psychologists and pediatricians: Opportunities for collaboration in primary care. American Psychologist, 69(4), 332-343.

Strosahl, K. (1998). Integrating behavioral health and primary care services: The primary mental health care model. In B Alexander (Ed.), Integrated primary care: The future of medical and mental health collaboration (pp. 139-166). New York, New York: W. W. Norton \& Co.

Talmi, A., \& Fazio, E. (2012). Commentary: Promoting health and well-being in pediatric primary care settings: Using health and behavior codes at routine well-child visits. Journal of Pediatric Psychology, 37(5), 496-502.

Tynan, W.D. (2016). Commentary: Integrated primary care psychology evolving with the affordable care act. Journal of Pediatric Psychology, 41(10), 1165-1167. doi: 10.1093/jpepsy/jsw086

Vogel, M. E., Malcore, S. A., Illes, R. C., \& Kirkpatrick, H. A. (2014). Integrated primary care: Why you should care and how to get started. Journal of Mental Health Counseling, 36(2), 130-144.

Westfall, J. M., Mold, J., \& Fagnan, L. (2007). Practice-based research—“Blue Highways" on the NIH roadmap. JAMA, 297(4), 403-406. 